\title{
Clinical profile of hypertension at a University Teaching Hospital in Nigeria
}

This article was published in the following Dove Press journal:

Vascular Health and Risk Management

I July 2010

Number of times this article has been viewed

\section{Arthur C Onwuchekwa Sunday Chinenye}

Department of Internal Medicine, University of Port Harcourt Teaching Hospital, Nigeria
Correspondence: AC Onwuchekwa Dept of Internal Medicine, University of Port Harcourt Teaching Hospital, Port Harcourt, Rivers State, Nigeria Tel +234803342 I872

Email ac_onwuchekwa@yahoo.com
Background: Hypertension in Nigeria is a widespread problem of immense social and economic importance because of its high prevalence and the severity of its complications.

Aim: To define the morbidity and mortality pattern of hypertension at the University of Port Harcourt Teaching Hospital (UPTH).

Method: Records of all patients admitted to the medical wards of the UPTH over a 5-year period with essential hypertension or any of its complications were retrieved from the ward and medical records and reviewed.

Result: A total of 780 hypertensive patients were reviewed, constituting $28.2 \%$ of all medical admissions. Only 424 (15.2\%) had complete records and were analyzed. Record keeping was poor. There were $173(41 \%)$ males and $251(59 \%)$ females with a male to female ratio of $1: 1.5$. The ages ranged from 18 years to 100 years with a mean of $56.5 \pm 16.2$. Stroke was responsible for 169 (39.9\%) hypertensive complications. Heart failure occurred in 97 (22\%) cases while renal failure and encephalopathy accounted for $40(9.4 \%)$ and $7(1.7 \%)$ hypertensive complications respectively. There were 99 deaths out of which 51 (51.5\%) were due to stroke, $14(14.12 \%)$ were due to heart failure, and $12(12.1 \%)$ were due to renal failure.

Conclusion: The contribution of systemic hypertension to the morbidity and mortality of adults at UPTH is quite significant.

Keywords: clinical profile, hypertension, University of Port Harcourt Teaching Hospital

\section{Introduction}

Hypertension has been acknowledged as one of the greatest and established risk factors for cardiovascular diseases. ${ }^{1}$ According to the 7 th report of the Joint National Committee on Prevention, Detection, Evaluation and Treatment of High Blood Pressure (JNC 7), the prevalence estimates worldwide for hypertension may be as much as 1 billion individuals, and approximately 7.1 million deaths per year may be attributable to hypertension. ${ }^{2}$

Attention was first drawn to the racial difference in hypertension between blacks and whites in 1932 by Adam. ${ }^{3}$ In a study involving 6000 blacks and 8000 whites, in New Orleans, he found a higher level of elevated blood pressure among blacks. Since then, various larger multicenter studies in the United States have shown that the prevalence of hypertension in the USA is much more common in blacks than in the whites. ${ }^{4,5}$

Early reports from Africa were of the view that hypertension was uncommon. In 1929 Donnison conducted a survey of East African males and found that up to the age of 40 years, the average blood pressure related to age closely resembled that found in Europeans. ${ }^{6}$ 
However, after that age, he found that the average blood pressure in the Africans fell, while it rose in the Europeans. From his clinical experience in a native hospital over a twoyear period, Donnison reported that he did not see a single case in hospital practice.

Similar studies up to the 1970 s showed a low prevalence or virtual absence, and no increase in blood pressure with age in sub-Saharan Africa.,

This picture has since changed. The World Health Organization (WHO) estimates that hypertension associated morbidity in sub-Saharan Africa may rise to $20 \%$ by the year $2020 .^{9}$

It is against this background that this descriptive study was performed to ascertain the morbidity and mortality pattern of hypertension at the University of Port Harcourt Teaching Hospital (UPTH) in the Niger Delta region of Nigeria. The study also aimed to identify other risk factors for the morbidity and mortality among patients reporting with essential hypertension at UPTH.

\section{Patients and methods}

\section{Setting}

Port Harcourt is the capital of Rivers State, the heartbeat of the oil industry in Nigeria. It has an international airport, two seaports, two petroleum refineries, a petrochemical industry, a big fertilizer plant, and a gas plant. The UPTH is a tertiary health institution located in the city. It is the main referral center for Rivers State and the neighboring states of Bayelsa, Abia, Delta, Imo, and Akwa Ibom - all in the oil-rich Niger Delta region. There are 500 beds among the various specialties in UPTH with 60 inpatient beds for adult admissions (30 beds for males and 30 for females).

Among the various professionals who reside in Port Harcourt, their various professional membership records show that there are about 30,000 engineers working in the different oil-related industries, 1,500 medical doctors (the majority of whom are in UPTH), and about 1000 lawyers.

\section{Patients}

Records of all patients admitted to the medical wards of UPTH with hypertension or any of the complications arising from hypertension over a 5-year period January 2002 to December 2006 were retrieved from the ward and medical records and reviewed.

The criteria for inclusion in the study were the occurrence of a systolic blood pressure of $\geq 140 \mathrm{mmHg}$ and/or diastolic blood pressure of $\leq 90 \mathrm{mmHg}$. The choice of 140/90 $\mathrm{mmHg}$ as a cut-off point is based on the JNC 7 criteria. ${ }^{2}$ Data extracted included the age, sex, occupation, social class, date of admission, comorbid factors, complications and outcome. The complications and outcome of hypertension were based on clinical, radiological, electrocardiographic, echocardiographic and biochemical results of patients. Any case in which the outcome was not certain was included as part of missing data.

\section{Statistics}

Data were analyzed using SPSS H statistical software (version II, SPSS Inc., Chicago, IL). The procedures followed were in accordance with UPTH institutional guidelines and the hospital ethics committee approved the study.

\section{Results}

There were a total of 2784 medical admissions during the period. Of these 1536 (55.2\%) were males and 1248 (44.8\%) were females. The number identified as having hypertension was $780(28.2 \%)$. Of the total, $424(12.2 \%)$ had sufficient data for analysis and these 424 patients form the basis for this report. The group comprised 173 (41\%) males and $251(59 \%)$ females. The male to female ratio was $1: 1.5$. The ages ranged from 18 years to 100 years with a mean of $56.5 \pm 16.2$ and a mode of 60 . The peak age was the 7 th decade. This was followed by the 6 th and 5 th decades (Table 1). Out of the 424 patients seen, 245 (57.8\%) were in social class $\mathrm{V}$, but there were only $9(2.1 \%)$ professionals such as doctors, engineers and lawyers, from social class I. (Table 2).

Of the 424 admissions, 91 (21.5\%) had diabetes mellitus. Only 20 patients $(5 \%)$ had hypercholesterolemia. One hundred and twenty eight patients $(30.2 \%)$ gave a history of alcohol intake while only 43 patients (10.1\%) smoked cigarettes. The body mass index (BMI) was done for 80 males and 112 females. A body mass index of $\geq 30$ which is indicative of obesity was found in $13(16 \%)$ males and 45 (40.1\%) females.

Table I Age and sex distribution of patients with hypertension

\begin{tabular}{llll}
\hline $\begin{array}{l}\text { Age group } \\
\text { In year }\end{array}$ & \multicolumn{2}{l}{ Number of patients } & Total \\
\cline { 2 - 3 } & Males & Females & \\
\hline $10-19$ & 2 & 2 & 4 \\
$20-29$ & 6 & 12 & 18 \\
$30-39$ & 21 & 22 & 43 \\
$40-49$ & 29 & 41 & 70 \\
$50-50$ & 40 & 38 & 78 \\
$60-69$ & 41 & 70 & 111 \\
$70-79$ & 24 & 39 & 63 \\
$80-89$ & 10 & 23 & 33 \\
90 and above & - & 4 & 4 \\
\hline
\end{tabular}


Table 2 Distribution of hypertension among social class

\begin{tabular}{llll}
\hline $\begin{array}{l}\text { Social } \\
\text { class }\end{array}$ & Description & Number & Percentage \\
\hline I & Natural rulers, professionals & 9 & 2.1 \\
II & Executive management workers & 12 & 2.8 \\
III & Skilled workmen, students & 36 & 9.1 \\
IV & Semi skilled craftsmen & 124 & 28.2 \\
V & Unskilled workers, farmers, & & \\
& traders, housewives, & & \\
& unemployed & 245 & 57.8 \\
Total & & $\mathbf{4 2 4}$ & 100 \\
\hline
\end{tabular}

Stroke was responsible for 169 (39.9\%) of admissions. Heart failure occurred in 97 (22\%) cases while renal failure and encephalopathy were responsible for $40(9.4 \%)$ and 7 $(1.7 \%)$ of hypertensive complications respectively.

Fifty-six patients (13.2\%) who had hypertension were admitted because of other unrelated illnesses (Table 3).

There were 99 (23.3\%) deaths due to complications of hypertension. Postmortem was not done. Stroke accounted for $51(51.5 \%)$ deaths while $14(14.12 \%)$ deaths were due to heart failure and $12(12.1 \%)$ deaths were due to renal failure (Table 4).

\section{Discussion}

The results from this study confirm the presently held view that the prevalence of hypertension is high in most African populations. ${ }^{10-12}$ The prevalence of hypertension of $28 \%$ among the inpatients in this series compares well with the result of $21 \%$ in Benin city ${ }^{13}$ and $30 \%$ in Tanzania, ${ }^{14}$ but is

Table 3 Other conditions for which hypertensive patients were admitted and outcome

\begin{tabular}{llll}
\hline Event & Survived & Died (\%) & Total \\
& $\mathbf{N}=\mathbf{3 2 5}$ & $\mathbf{N}=\mathbf{9 9}$ & $\mathbf{N}=\mathbf{4 2 4}$ \\
\hline None & $28 \mathrm{I}$ & 87 & 368 \\
Ca prostate & 4 & $\mathrm{I}(20)$ & 5 \\
Pelvic mass & - & $\mathrm{I}(\mathrm{I00})$ & $\mathrm{I}$ \\
Limb girdle muscular dystrophy & $\mathrm{I}$ & $-(0)$ & $\mathrm{I}$ \\
Cord compression & $\mathrm{I}$ & $-(0)$ & $\mathrm{I}$ \\
Seizure disorder & 2 & $\mathrm{I}(33.3)$ & 3 \\
Benign prostatic hypertrophy & 6 & $2(25)$ & 8 \\
Elephantiasis & $\mathrm{I}$ & $-(0)$ & $\mathrm{I}$ \\
Lower gastrointestinal bleeding & $\mathrm{I}$ & $\mathrm{I}(50)$ & 2 \\
Endometrial cancer & 2 & $-(0)$ & 2 \\
Pulmonary tuberculosis & 6 & $2(25)$ & 8 \\
HIV/AIDS & 7 & $2(22.2)$ & 9 \\
Parkinson's disease & 2 & $\mathrm{I}(33.3)$ & 3 \\
Peptic ulcer disease & 3 & $-(0)$ & 3 \\
Chronic liver disease & 3 & $\mathrm{I}(25)$ & 4 \\
Goiter & 4 & $-(0)$ & 4 \\
Lobar pneumonia & $\mathrm{I}$ & $-(0)$ & $\mathrm{I}$ \\
\hline & & & \\
\hline
\end{tabular}

much higher than the previous reports of $8.8 \%$ by Smith in Lagos $^{15}$ and $9.3 \%$ by Abengowe in Kaduna. ${ }^{16}$ This may be because the criterion for hypertension diagnosis used in this current study was $140 / 90 \mathrm{mmHg}$ as against the previous studies which used 160/95 mmHg. Valid conclusions from this present study are hindered by the poor record keeping noted. This is underscored by the finding that only 424 out of 780 patients with hypertension had sufficient record to be analyzed. Several case notes could not be retrieved from the Medical Records Department. The medical records in UPTH like in most centers in developing countries have not been computerized. Some records taken out of the library for research purposes had not been returned. There was however, no bias in the record keeping. These handicaps are part of the relevant lessons from this study. Similar experiences have been encountered previously in this center ${ }^{17}$ and in other centers in the subregion. ${ }^{18,19} \mathrm{~A}$ case for improving standards in record keeping has been made even in the developed world. ${ }^{20}$ The results would have been strengthened if all the records had been retrieved and all the data entered. The current high prevalence of hypertension observed in the African suggests that certain factors may have come into operation in recent years which act as trigger factors in the development of hypertension. Such risk factors include environmental stress, dietary habits and physical inactivity from use of automobile transportation in most urban dwellers.

In this study, blood pressure increased with age up to the 7 th decade. Thereafter there was a decline. This decline in the incidence of hypertension after the 7th decade suggests that hypertension may have caused a significant proportion of deaths. Prevalence of hypertension in this study was greater in females than males, which is contrary to other reports from many centers in Nigeria. ${ }^{15,21,22}$ However in Lagos, Johnson found a higher prevalence of females than males after the age of 45 years. ${ }^{23}$ This could be because more of the females were obese than their male counterparts. Obesity is a universally acknowledged risk factor for hypertension. ${ }^{2}$ The present study is in agreement with those of others, Kadiri et al in Ibadan, ${ }^{24}$ Johnson in Lagos, ${ }^{23}$ and Abengowe in Kaduna, ${ }^{16}$ who reported that hypertension is common among the low socioeconomic groups in Nigeria. In a national survey by Akinkugbe et $\mathrm{al},{ }^{25}$ the prevalence of hypertension seemed higher at both extremes of the socioeconomic spectrum. The high incidence of hypertension among the lowest socioeconomic group in this series may be related to the stressful life they live, and the deprivation which the system exposes them to: overcrowding, incessant power failure, the rush for public transport, poor diet, and lack of access to health facilities. From this study, it seems that being 
Table 4 Complications of hypertension and the fatality rate

\begin{tabular}{|c|c|c|c|c|c|}
\hline Complication & Male $\mathbf{N}=$ & Female $\mathbf{N}=$ & Total N = $424(\%)$ & No of deaths & Fatality rate \\
\hline Stroke & 71 & 98 & $169(39.9)$ & 51 & 30 \\
\hline Heart failure & 37 & 60 & $97(22.9)$ & 14 & 15 \\
\hline Renal failure & 18 & 22 & $40(9.4)$ & 12 & 30 \\
\hline Encephalopathy & 2 & 5 & $7(1.7)$ & I & 14 \\
\hline Dementia & I & I & $2(0.5)$ & - & 0 \\
\hline None & 24 & 32 & $56(13.2)$ & 15 & 27 \\
\hline Stroke and heart failure & 5 & 10 & $15(3.5)$ & 3 & 20 \\
\hline Heart failure and renal failure & 10 & 16 & $26(6.1)$ & 2 & 8 \\
\hline Stroke/heart failure renal failure & 2 & 2 & $4(0.9)$ & I & 25 \\
\hline Stroke and renal failure & 3 & 5 & $8(1.9)$ & - & 0 \\
\hline
\end{tabular}

a professional carries a lower risk of developing hypertension or its complications compared to the unemployed or a civil servant, which is contrary to the report of the national survey. This could be because the professionals are relatively wealthier and could afford to buy their drugs when diagnosed. Most of the oil companies operating in the region own or retain clinics for their staff. Other professionals would prefer to attend private clinics rather than government-owned ones in order to avoid bureaucratic bottlenecks and reduce waiting time. That notwithstanding, when complications from hypertension, such as stroke, heart failure and renal failure arise, most of such patients are referred to UPTH which has the facilities and resource persons to handle such complications. Against this background, we think that the over 32,500 professionals in the local area is a large enough number to yield much more than the $9(2.1 \%)$ patients seen in UPTH in 5 years. Another reason for the low incidence of hypertension among the professionals could be that they (professionals) also had easier access to the mass media which could influence their lifestyle to attain more effective blood pressure control. In a study in Kano city, northwest Nigeria, on the compliance to medication among hypertensive patients, Kabir et $\mathrm{al}^{26}$ found that the educated and those with higher incomes had better compliance and consequently fewer complications. About $50 \%$ of hypertensive patients were not aware that they had hypertension. This compares with the finding in Kerala, ${ }^{27}$ an urban district in India where about $61 \%$ of middle-aged hypertensive patients were unaware of their condition. Similarly, $74 \%$ hypertensive patients in Ga district, a rural community in Ghana, ${ }^{28}$ did not know that they were hypertensive. In Benin, ${ }^{13}$ south of Nigeria, $45.5 \%$ of hypertensive patients were not diagnosed before they presented with complications. The lack of awareness in this large segment of the patient population may be partly due to the poorly-developed health services and lack of adequate mass media campaigns in enlightening the public on the need for routine blood pressure checks.
The number of hypertensive patients with diabetes mellitus in this study was 91 (21.5\%). Diabetes is a major risk factor for cardiovascular disease (CVD). This figure is much higher than the estimated $5 \%-7 \%$ in most of urban sub-Saharan Africa. ${ }^{29}$ This could be due to the fact that the oil industry in the city of Port Harcourt has attracted so many foreigners with its attendant westernization of dietary habits. Hypercholesterolemia was found in 5\% of the patients in this study, lower than the finding at the University College Hospital Ibadan (UCH), southwest of Nigeria where $9.6 \%$ (5.4\% of males and $4.2 \%$ of females $)^{30}$ had hypercholesterolemia. This could be dietary. Presently, the prevalence of coronary artery disease is still low in Africa. ${ }^{31}$ However, the risk factors of hypertension, obesity, and hypercholesterolemia associated with coronary heart disease are emerging. ${ }^{32}$ The percentage of obese patients $(\mathrm{BMI}>30)$ in this study was $40 \%$ for females and $16 \%$ for males. This figure is higher than the $33 \%$ of obese females but lower than the $27.5 \%$ of obese males among hypertensive patients attending UCH Clinic. The reason for this could be that more males in Port Harcourt are involved in more physical activity in the oil industry than residents in Ibadan, which is a civil servant city. While $30.2 \%$ of these patients took alcohol, only $10 \%$ of patients smoked cigarettes. Both of these products are relatively cheap. Health promotion efforts should be intensified so that people could give up smoking and drinking, thereby avoiding their attendant health problems.

The most common hypertensive complication was stroke which occurred in 169 (39.9\%) of patients, followed by congestive cardiac failure in $97(22.9 \%)$ and chronic renal failure in $40(9.4 \%)$. Dementia was rare, being found in only $2(0.5 \%)$ patients. This is similar to the finding in Benin where stroke was the commonest complication, followed by congestive cardiac failure, and chronic renal failure in that order. ${ }^{13}$ Thus, stroke is the commonest cardiovascular event 
encountered from hypertension at UPTH. Cooper et $\mathrm{al}^{33}$ found that stroke has been by far the most common clinical sequelae of hypertension in African populations.

Similarly, mortality from stroke was highest with $51(30 \%)$ deaths, followed by congestive cardiac failure with 14 (14.4\%) deaths, and chronic renal failure with 12 (30\%) deaths. This constituted $6.9 \%$ of overall medical mortality during the study period. Thus, stroke prevention through control of hypertension should be given top priority.

In a study two decades earlier, on the mortality patterns in the medical wards of UPTH,${ }^{34}$ hypertension and its complications constituted a major cause of death, with stroke accounting for $15.9 \%$ of overall mortality, while heart failure and renal failure had mortalities of $9.3 \%$ and $3.1 \%$ respectively. A more recent study of the pattern of geriatric admissions in $\mathrm{UPTH}^{35}$ showed that cardiovascular diseases were the most common cause of morbidity. They accounted for $43.7 \%$ of all admissions of which $47.4 \%$ of these cardiovascular admissions were caused by stroke. Only $3.4 \%$ of the geriatric admissions were caused by renal diseases. Hypertension was the main cause of these cardiovascular morbidities. ${ }^{35}$ It would appear that no program has been instituted to arrest this menace and that the adverse effects of hypertension are on the increase.

\section{Conclusion}

Hypertension is a significant health problem in Port Harcourt. It is common among the lowest socioeconomic class. Efforts should be made to create hypertension awareness targeting the lowest segment of society. Campaigning for life style changes and the need for regular blood pressure checks should be emphasized. There is a need for establishment of a stroke registry in UPTH. Efficient record keeping, good storage of records, and a system for prompt retrieval of patients' hospital data are desired.

\section{Acknowledgment/Disclosure}

We are grateful to the Medical Records Department, UPTH for efforts to make the patients' folders available. The authors report no conflicts of interest in this work.

\section{References}

1. Miura K. Strategies for prevention and management of hypertension throughout life. J Epidemiol. 2004;14:112-117.

2. Chobanian AV, Bakris GL, Black HR, et al. Seventh report of the joint national committee on prevention, detection, evaluation and treatment of high blood pressure. Hypertension. 2003;42:1206-1252.

3. Adam JM. Some racial differences in blood pressures and morbidity in a group of whites and colored workmen. Am J Med Sci. 1932; 184:342-349.
4. Burt VL, Cutler JA, Higgins M, et al. Trends in the prevalence, awareness, treatment, and control of hypertension in the adult US population: Data from the Health Examination Surveys. 1960 to 1991. Hypertension. 1995;26:60-69.

5. Lackland DT, Keil JE. Epidemiology of hypertension in African Americans. Semin Nephrol. 1996;16:63-70.

6. Donnison C. Blood pressure in the African natives; its bearing upon aetiology of hyperpiesa and arteriosclerosis. Lancet. 1929;1:6-7.

7. Pobee J, Larbi E, Belcher D, Wurapa FK, Dodu SR. Blood pressure distribution in a rural Ghanaian population. Trans R Soc Trop Med Hyg. 1977;71:66-72.

8. Sever PS, Gordon D, Peart WS, Beighton P. Blood pressure and its correlates in urban and tribal Africa. Lancet. 1980;316:60-64.

9. Van der Sande MA. Cardiovascular disease in sub-Saharan Africa: a disaster waiting to happen. Neth J Med. 2003;61:32-36.

10. Opie LH, Seedat YK. Hypertension in sub-Saharan African populations. Circulation. 2005;112:3562-3568.

11. Connor M, Rheeder P, Bryer A, et al. The South African Stroke Risk in General Practice study. S Afr Med J. 2005;95:334-339.

12. Kengne AP, Awah PK, Fezeu L, Mbanya JC. The burden of high blood pressure and related risk factors in urban sub-Saharan Africa. Evidence from Douala in Cameroon. Afr Health Sci. 2007;7:38-44.

13. Ukoh VA. Admission of hypertensive patients at the University of Benin Teaching Hospital. East Afr Med J. 2007;84:329-335.

14. Edward R, Unwin N, Mugusi F, et al. Hypertension prevalence and care in an urban and rural area of Tanzania. J Hypertens. 2000;18:145-152.

15. Smith JA. Arterial hypertension patients at the University of Lagos Teaching Hospital, Nigeria. West Afr J Med. 1966;15:97-104.

16. Abengowe CU, Jain JS, Siddique AK. Pattern of hypertension in the northern savanna of Nigeria. Trop Doct. 1980;10:3-8.

17. Eke N, Sapira MK. Prostate Cancer in Port Harcourt, Nigeria: features and outcome. Nig J Surg Res. 2002;4:34-44.

18. Edet EE, Ikpeme BM, Ndifon WO, Ovo-Ita AE. Factors associated with missed opportunities to immunize with tetanus toxoid at a tertiary health institution in Nigeria. Cent Afr J Med. 1998;44:199-202.

19. Hesse IF, Mensah A, Asante DK, Lartey M, Neequaye A. Characteristics of adult tetanus in Accra. West Afr J Med. 2003;22;291-294.

20. Pullen I, Loudon J. Improving standards in clinical record keeping. $A d v$ Psychiatr Treat. 2006;12:280-286.

21. Abrahams DG, Alele CA, Barnard BG. The systemic blood pressure in a rural West Africa Community. West Afr Med J. 1960;9:45-58.

22. Oviasu VO. Prognosis of hypertension among Nigerians. Nig Med J. 1980;4:247-250.

23. Johnson TO. Arterial blood pressures and hypertension in an urban African population sample. Br J Prev Soc Med. 1971;25:26-33.

24. Kadiri S, Olutade BO, Osobamiro O. Factors influencing the development of malignant hypertension in Nigeria. J Hum Hypertens. $2000 ; 14 ; 171-174$

25. Akinkugbe OO. Non-Communicable diseases in Nigeria. Final report of a national survey. Lagos: Federal Ministry of Health - National Expert Committee on NCD. 1997;12-41.

26. Kabir M, lliyasu Z, Abubakar IS, Jibril M, Compliance to medication among hypertensive patients in Murtala Mohammed Specialist Hospital, Kano, Nigeria. J Community Med Prim Health Care. 2004;16-20.

27. Zachariah MG, Thankappan KR, Alex SC, Sarma PS, Varsam RS. Prevalence, correlates, awareness, treatment, and control of hypertension in a middle-aged urban population in Kerala. Indian Heart J. 2003; 55:245-251.

28. Addo J, Amoah AG, Koram KA. The changing patterns of hypertension in Ghana; a study of four rural communities in the Ga District. Ethn Dis. 2006;16:894-899.

29. Kengne AP, Amoah AGB, Mbanya J-C. Cardiovascular complications of diabetes mellitus in sub-Saharan Africa. Circulation. 2005; 112:3592-3601.

30. Yekeen LA, Sanusi RA, Ketiku AO. Prevalence of obesity and high level of cholesterol in hypertension: Analysis of data from the University College Hospital Ibadan. African Journal of Biomedical Research. $2003 ; 6: 129-132$. 
31. Sani MU, Adamu B, Mijinyawa MS, et al. Ischaemic heart disease in Aminu Kano Teaching Hospital Kano, Nigeria: a 5 years review. Niger J Med. 2006;15:128-131.

32. Dagogo-Jack S, Odia OJ, Myocardial infarction in Nigerian Africans. Orient J Med. 1990;2:129-132.

33. Cooper RS, Amoah AG, Mensah GA. High blood pressure: the foundation for epidemic cardiovascular diseases in African populations. Ethn Dis. 2003 Summer;13(2 Suppl 2):S48-S52.
34. Odia OJ, Wokoma FS. Mortality pattern in the medical wards of a Nigerian Teaching Hospital. Orient J Med. 1992;4:96-100.

35. Onwuchekwa AC, Asekomeh EG. Geriatric admissions in a developing country: experience from a tertiary centre in Nigeria. Ethn Dis. 2009; 19:359-362.

\section{Publish your work in this journal}

Vascular Health and Risk Management is an international, peerreviewed journal of therapeutics and risk management, focusing on concise rapid reporting of clinical studies on the processes involved in the maintenance of vascular health; the monitoring, prevention and treatment of vascular disease and its sequelae; and the involvement of metabolic disorders, particularly diabetes. This journal is indexed on PubMed Central and MedLine. The manuscript management system is completely online and includes a very quick and fair peer-review system, which is all easy to use. Visit http://www.dovepress.com/ testimonials.php to read real quotes from published authors.

Submit your manuscript here: http://www.dovepress.com/vascular-health-and-risk-management-journal 